OPEN ACCESS

Edited by:

Andrea Gaedigk,

Children's Mercy Hospital, USA

Reviewed by:

Hans Neubauer,

University of Düsseldorf, Germany Ilpo Huhtaniemi,

Imperial College London, UK

${ }^{*}$ Correspondence:

Ulrich M. Zanger

uli.zanger@ikp-stuttgart.de

Specialty section:

This article was submitted to

Pharmacogenetics

and Pharmacogenomics,

a section of the journal

Frontiers in Pharmacology

Received: 12 January 2017 Accepted: 13 March 2017

Published: 27 March 2017

Citation:

Ryu CS, Klein K and Zanger UM

(2017) Membrane Associated

Progesterone Receptors:

Promiscuous Proteins with Pleiotropic

Functions - Focus on Interactions

with Cytochromes P450.

Front. Pharmacol. 8:159.

doi: 10.3389/fphar.2017.00159

\section{Membrane Associated Progesterone Receptors: Promiscuous Proteins with Pleiotropic Functions - Focus on Interactions with Cytochromes P450}

\author{
Chang S. Ryu ${ }^{1,2}$, Kathrin Klein ${ }^{1,2}$ and Ulrich M. Zanger ${ }^{1,2 *}$ \\ ${ }^{1}$ Department of Molecular and Cell Biology, Dr. Margarete Fischer-Bosch-Institute of Clinical Pharmacology, Stuttgart, \\ Germany, ${ }^{2}$ Eberhard-Karls-University, Tübingen, Germany
}

Membrane-associated progesterone receptors (MAPR) are a group of four rather small, partially homologous proteins, which share a similar non-covalent heme-binding domain that is related to cytochrome b5, a well-known functional interaction partner of microsomal cytochrome P450 (CYP) monooxygenase systems. Apart from their structural similarities the four proteins progesterone membrane component 1 (PGRMC1, also referred to as IZA, sigma-2 receptor, Dap1), PGRMC2, neudesin (NENF) and neuferricin (CYB5D2) display surprisingly divergent and multifunctional physiological properties related to cholesterol/steroid biosynthesis, drug metabolism and response, iron homeostasis, heme trafficking, energy metabolism, autophagy, apoptosis, cell cycle regulation, cell migration, neural functions, and tumorigenesis and cancer progression. The purpose of this mini-review is to briefly summarize the structural and functional properties of MAPRs with particular focus on their interactions with the CYP system. For PGRMC1, originally identified as a non-canonical progesterone-binding protein that mediates some immediate non-genomic actions of progesterone, available evidence indicates mainly activating interactions with steroidogenic CYPs including CYP11A1, CYP21A2, CYP17, CYP19, CYP51A1, and CYP61A1, while interactions with drug metabolizing CYPs including CYP2C2, CYP2C8, CYP2C9, CYP2E1, and CYP3A4 were either ineffective or slightly inhibitory. For the other MAPRs the evidence is so far less conclusive. We also point out that experimental limitations question some of the previous conclusions. Use of appropriate model systems should help to further clarify the true impact of these proteins on CYP-mediated metabolic pathways.

Keywords: cytochrome P450, membrane-associated progesterone receptor, neudesin, neuferricin, PGRMC1, PGRMC2, protein-protein interaction

\section{INTRODUCTION}

Inter- and intraindividual variability in the expression and activity of drug metabolizing enzymes, transporters and their regulators is a major determinant of drug response, both in terms of drug efficacy and adverse events. The cytochrome P450 enzymes, a superfamily of microsomal and mitochondrial hemoproteins (CYP), are particularly variable between and within subjects (Zanger and Schwab, 2013). Despite half a century of pharmacogenetic research, much of the 
interindividual variation remains unexplained (Meyer, 2004; Lauschke and Ingelman-Sundberg, 2015). This "dark variation" may be explained by so far unidentified or unexplored genes that influence drug metabolism at the level of protein-protein interactions (PPI). The multiple monooxygenase functions of microsomal CYP enzymes strictly depend on PPI with the single microsomal flavoprotein NADPH:cytochrome P450 oxidoreductase (POR) to allow electron transfer from NADPH to the heme iron (Pandey and Fluck, 2013; Kandel and Lampe, 2014). Since POR is present in the endoplasmic reticulum (ER) at sub-stoichiometric amounts compared to CYP, it has been proposed that their interactions involve transient oligomeric complexes (Backes and Kelley, 2003). In contrast to POR, the small hemoprotein cytochrome b5 (CYB5), which is located together with CYB5-reductase and the other components on the cytoplasmic side of the ER, is not an obligatory electron donor for CYPs but acts as modulator of enzyme activity in CYP- and sometimes substrate-dependent way (Henderson et al., 2015). For a long time, POR and CYB5 were the only proteins known to functionally interact with CYPs during the microsomal monooxygenase reaction. Only in recent years new PPI candidates for cytochromes P450 have been considered (see other articles in this Research Topic).

A particularly intriguing group of proteins are the socalled "membrane-associated progesterone receptor" (MAPR) proteins. The term emphasizes their common ability to bind progesterone and to elicit rapid steroidal effects independent of the classical steroid hormone receptors (Wehling, 1997; Mifsud and Bateman, 2002). Following the initial purification of a highaffinity progesterone-binding protein (later termed progesterone receptor membrane component 1, PGRMC1) from porcine liver membranes and cDNA cloning (Meyer et al., 1996; Gerdes et al., 1998), MAPRs were recognized as evolutionarily conserved, distant homologs of CYB5, that can principally interact with CYPs and modulate their functions (Min et al., 2004; Hughes et al., 2007).

The purpose of this review is to provide an overview and critical assessment of the studies elucidating potential interactions of MAPRs with CYPs. Apart from this, MAPRs interact with an increasing number of different proteins and are involved in a wide variety of cellular functions including cholesterol and steroid homeostasis, cell cycle regulation, cell migration, neurogenesis, autophagy, heme homeostasis and more that are only briefly mentioned but not the focus of this review. Readers interested in these aspects are referred to excellent reviews by others (Losel et al., 2008; Ahmed et al., 2012; Kimura et al., 2012; Neubauer et al., 2013; Cahill et al., 2016; Hasegawa et al., 2016).

\section{MOLECULAR, BIOCHEMICAL AND CELLULAR PROPERTIES OF MAPRS}

The four MAPR proteins PGRMC1, PGRMC2, neuferricin and neudesin share a homologous CYB5-like heme/steroidbinding domain but lack homology with the classical nuclear or membrane-bound steroid receptors (Mifsud and Bateman, 2002;
Min et al., 2005; Kimura et al., 2012). Recent crystallographic analyses confirmed the hemoprotein nature of PGRMC1 with a special five-coordinated heme iron involving Tyr113, as opposed to the six-coordinated heme with two axial histidines in CYB5 (Min et al., 2005; Kaluka et al., 2015; Kabe et al., 2016). Interestingly, this difference allows human PGRMC1 to form stable homodimers through hydrophobic heme-heme stacking interactions, explaining earlier observations of dimeric complexes (Min et al., 2004; Kabe et al., 2016). Since the hemebinding residues are conserved among MAPRs, these proteins may all share the ability of heme-dependent homo- and/or heterodimerization (Peluso et al., 2014). Although PGRMC1 had originally been defined as a component of a progesterone-binding protein complex with affinities in the nM range (Meyer et al., 1996), it remained questionable whether progesterone actually binds directly to PGRMC1 itself. A recent study provided first qualitative spectroscopic evidence that this is indeed the case, while it is still not proven for other MAPRs (Kaluka et al., 2015).

\section{PRGMC1}

PRGMC1 is predominantly expressed in mammalian liver and kidney but also found in steroidogenic and reproductive tissues, brain, breast, heart, lung, skeletal muscle, pancreas, and other organs (Gerdes et al., 1998; Kimura et al., 2012). Typically it is colocalized with CYPs in the smooth ER, but it has also been localized in the nucleus, cytoplasm, plasma membrane, and mitochondria (Kimura et al., 2012; Piel et al., 2016). Expression is inducible by carcinogens, including dioxin (Selmin et al., 1996), and increased in breast and other tumors, where it contributes to cancer progression (Neubauer et al., 2008; Ruan et al., 2017). Reported physiological functions affected by PGRMC1 include cholesterol/steroid biosynthesis and metabolism (see below), iron homeostasis and heme trafficking by regulating hepcidin expression and ferrochelatase activity (Craven et al., 2007; Li et al., 2016; Piel et al., 2016), promotion of autophagy through interaction with MAP1LC3B (Mir et al., 2013), regulation of cell cycle, proliferation, and cell death (Peluso et al., 2014), maintenance of female reproductive functions in PGRMC1 conditional knock-out mice (McCallum et al., 2016), cell migration and invasion (Sueldo et al., 2015), amyloid beta binding and synaptotoxicity in a mouse model of Alzheimer's disease (Izzo et al., 2014), and others (Losel et al., 2008; Ahmed et al., 2012; Neubauer et al., 2013; Cahill et al., 2016; Hasegawa et al., 2016). A growing number of studies supports furthermore a role of PGRMC1 in drug response and as potential drug target, e.g., by increasing susceptibility to tyrosine kinase inhibitors (Ahmed et al., 2010), decreasing doxorubicin cytotoxicity (Lin et al., 2015), or mediating atypical antipsychotic drug-induced lipid disturbances (Cai et al., 2015). Importantly, in 2011 PGRMC1 was identified as the elusive sigma 2 receptor (S2R), an intracellular orphan receptor that binds to many drugs and that is abundant in liver and kidney (Xu et al., 2011; Ahmed et al., 2012).

\section{PGRMC2}

PGRMC2 harbors a structurally similar CYB5 domain as PGRMC1, while there are differences in the N-terminal transmembrane domain (Cahill, 2007). Human PGRMC2 
protein is 247 amino acids in length. Despite its structural similarities to PGRMC1, PGRMC2 has been less well studied (Wendler and Wehling, 2013; Hasegawa et al., 2016). Expression appears to be ubiquitous with similar intracellular localization (Chen et al., 2010; Intlekofer and Petersen, 2011). In SKOV-3 ovarian cancer cells no differences between PGRMC1 and 2 in regard to cell viability or response to cisplatin and progesterone were found, but only PGRMC2 inhibited cell migration (Albrecht et al., 2012). PGRMC2 was also implicated in cell cycle regulation (Peluso et al., 2014).

\section{Neudesin}

Neudesin was originally identified as a mouse secreted protein with neurotrophic activity and termed neuron-derived neurotrophic factor (NENF) (Kimura et al., 2005). In adult mice, neudesin was expressed preferentially in the CNS spinal cord but also in several peripheral tissues (Kimura et al., 2005, 2012). NMR studies suggested a similar structure with a potential heme-binding pocket (Han et al., 2012). The physiological roles of neudesin as a secreted protein appear to be significantly different from PGRMC1/2, including particularly neurotrophic activity that required heme binding and was mediated through mitogen-activated protein (MAP) and phosphatidylinositol 3-kinase (PI-3K) pathways (Kimura et al., 2005). Several neurological functions have been studied in knockout mice as summarized elsewhere (Ohta et al., 2015). Extracellular/secreted neudesin may be involved in carcinogen resistance and tumor cell immortalization, although specific receptors remain unknown (Ohta et al., 2015).

\section{Neuferricin}

Neuferricin (CYP5D2) was discovered via a homologybased search of the CYB5-like heme/steroid-binding domain of neudesin, alternatively termed cytochrome B5 Domain Containing 2 (CYB5D2) (Kimura et al., 2010). Neuferricin is also widely expressed in several tissues including the CNS, heart, adrenal glands, and kidneys. Human neuferricin is 264 amino acids in length and includes a cleavable signal sequence at its $\mathrm{N}$ terminus followed by a heme-binding domain that may involve aspartic acid (D86) instead of tyrosine in heme binding (Bruce and Rybak, 2014). CYB5D2 can be detected as secreted hemoprotein in some cell lines but also colocalized with POR in the ER (Xie et al., 2011; Bruce and Rybak, 2014). Ectopic CYB5D2 expression inhibited cell proliferation and anchorage-independent colony growth of HeLa cells (Bruce and Rybak, 2014).

\section{SPECIFIC INVOLVEMENT OF MAPRS IN CYP FUNCTIONS}

The available evidence suggesting that MAPR proteins can interact with the microsomal CYP-monooxygenase system to modulate its function is based on different species from yeast to human, various experimental systems, and relates to CYP enzymes catalyzing steroidogenic or xenobiotic reactions (Table 1). The levels of interactions may include not only physical
PPIs but also indirect influences via heme transfer, heme and iron homeostasis, and transcriptional regulation (Figure 1).

\section{PGRMC1}

First indications for a link between PGRMC1 and CYP function came from two independent studies. Identification of the adrenal "inner zone antigen" (IZA) as a MAPR member (Raza et al., 2001), its localization in both steroidogenic and steroid metabolizing tissues and the fact that an anti-IZA monoclonal antibody decreased certain adrenal steroidhydroxylase activities led the authors to suggest a function in steroid hormone biosynthesis and/or metabolism (Min et al., 2004). By coexpressing IZA/PGRMC1 with CYP21A2, CYP11B1 or CYP17 in COS-7 cells they found differential effects, namely enhancement of progesterone 21-hydroxylation, no effect on progesterone $11 \beta$ - or $17 \alpha$-hydroxylation, and activation of the CYP17-catalyzed 17-20 lyase reaction (Min et al., 2004, 2005). About at the same time a search for novel yeast genes involved in DNA damage response led to the identification of Dap1 (Hand et al., 2003). Steroid analyses of Saccharomyces cerevisiae yeast cells lacking Dap1 revealed decreased levels of ergosterol but increased levels of its intermediates, suggesting a partial defect in sterol synthesis by lanosterol-14-demethylase, the highly conserved yeast-essential Erg11/CYP51 (Hand et al., 2003). Genetic follow-up studies supported a model in which heme binding by Dap1 is required to activate Erg11/CYP51, although a Dap1-Erg11 complex could not be directly detected by immunoprecipitation experiments (Mallory et al., 2005).

Further evidence for a role of Dap1/PGRMC1 in CYP function was provided by Hughes et al. (2007) working with Schizosaccharomyces pombe. After confirming that fission yeast Dap1 is also a hemoprotein and directly binds to and activates enzymatic activities of CYP51A1 (Erg11) and CYP61A1 (Erg5), they investigated whether PGRMC1 is required for cholesterol synthesis in mammals (Hughes et al., 2007). RNA interferencemediated knock-down of hPGRMC1 in HEK293 cells resulted in lanosterol accumulation, indicating that PGRMC1 was required for the demethylation of lanosterol by the Erg11 homolog, CYP51A1. Using a coexpression/coimmunoprecipitation approach PGRMC1 was shown to form a stable complex with CYP51A1 (Hughes et al., 2007). The authors applied the latter experiment also to CYP7A1, CYP21A2, and CYP3A4, demonstrating physically stable PGRMC1-CYP complexes in all cases. PGRMC1 was later shown to also activate CYP19 aromatase (Ahmed et al., 2012). Collectively these studies strongly suggest the ability of PGRMC1 to form functional PPIs with steroidogenic and possibly other CYPs. Interestingly, the documented functional influence of PGRMC1 on various steroidogenic CYPs appeared to be generally positive.

The above mentioned ability of PGRMC1 to complex with CYP3A4 first indicated the possibility that PGRMC1 may also interact with drug metabolizing P450s (Hughes et al., 2007). Although the authors emphasized the apparent existence of stoichiometric and physically stable complexes, it should be kept in mind that the experimental conditions of overexpressing tagged and manipulated proteins were quite artificial and that it 
TABLE 1 | Functional interactions between membrane-associated progesterone receptors (MAPR) proteins and cytochrome P450 system.

\begin{tabular}{|c|c|c|c|c|c|}
\hline MAPR & CYP & System & Enzymatic activity & Direction of influence & Reference \\
\hline IZA/PGRMC1 (rat) & CYP21A2 (rat) & $\begin{array}{l}\text { Inhibition by anti-IZA } \\
\text { monoclonal antibody }\end{array}$ & Progesterone 21-hydroxylase & Activation & Laird et al., 1988 \\
\hline IZA/PGRMC1 (rat) & CYP21A2 (rat) & COS-7 cell coexpression & Progesterone 21-hydroxylase & Activation & Min et al., 2004 \\
\hline IZA/PGRMC1 (rat) & CYP17 (guinea pig) & COS-7 cell coexpression & Progesterone $17 \alpha$-hydroxylase & Little or no influence & Min et al., 2005 \\
\hline IZA/PGRMC1 (rat) & CYP17 (guinea pig) & COS-7 cell coexpression & $\begin{array}{l}17 \alpha \text {-Hydroxyprogesterone } \\
17-20 \text { lyase }\end{array}$ & Activation & Min et al., 2005 \\
\hline IZA/PGRMC1 (rat) & CYP11B1 (rat) & COS-7 cell coexpression & Progesterone $11 \beta$-hydroxylase & Little or no influence & Min et al., 2004 \\
\hline PGRMC1 (human) & CYP19A1 (human) & $\begin{array}{l}\text { CYP19-engineered MCF-7 } \\
\text { human breast cancer cells } \\
\text { RNAi knockdown }\end{array}$ & $\begin{array}{l}\text { Androst-4-ene-3,17-dione } \\
\text { conversion }\end{array}$ & Activation & Ahmed et al., 2012 \\
\hline $\begin{array}{l}\text { Dap1/PGRMC1 } \\
\text { (S. cerevisiae) }\end{array}$ & CYP51A1 (S. cerevisiae) & S. cerevisiae genetics & Lanosterol-14-demethylase & Activation & $\begin{array}{l}\text { Hand et al., } 2003 \\
\text { Mallory et al., } 2005\end{array}$ \\
\hline $\begin{array}{l}\text { Dap1/PGRMC1 } \\
\text { (S. pombe) }\end{array}$ & CYP51A1 (S. pombe) & $\begin{array}{l}\text { S. pombe strain lacking } \\
\text { DAP1 }\end{array}$ & Lanosterol-14-demethylase & Activation & Hughes et al., 2007 \\
\hline $\begin{array}{l}\text { Dap1/PGRMC1 } \\
\text { (S. pombe) }\end{array}$ & CYP61A1 (S. pombe) & $\begin{array}{l}\text { S. pombe strain lacking } \\
\text { DAP1 }\end{array}$ & Lanosterol-22-desaturase & Activation & Hughes et al., 2007 \\
\hline PGRMC1 (rabbit) & CYP2C2 (rabbit) & $\begin{array}{l}\text { HEK293, HepG2 cell } \\
\text { coexpression }\end{array}$ & $\begin{array}{l}\text { Luciferin } 6^{\prime} \text { methyl ether } \\
\text { O-demethylation }\end{array}$ & Inhibition & $\begin{array}{l}\text { Szczesna-Skorupa } \\
\text { and Kemper, } 2011\end{array}$ \\
\hline PGRMC1 (human) & CYP2C8 (human) & $\begin{array}{l}\text { HEK293, HepG2 cell } \\
\text { coexpression }\end{array}$ & $\begin{array}{l}\text { Luciferin } 6^{\prime} \text { methyl ether } \\
\text { O-demethylation }\end{array}$ & Inhibition & $\begin{array}{l}\text { Szczesna-Skorupa } \\
\text { and Kemper, } 2011\end{array}$ \\
\hline PGRMC1 (human) & CYP3A4 (human) & $\begin{array}{l}\text { HEK293, HepG2 cell } \\
\text { coexpression }\end{array}$ & $\begin{array}{l}\text { Luciferin } 6 \text { ' pentafluorobenzyl } \\
\text { ether depentafluorobenzylation }\end{array}$ & Inhibition & $\begin{array}{l}\text { Szczesna-Skorupa } \\
\text { and Kemper, } 2011\end{array}$ \\
\hline PGRMC1 (human) & CYP2C9 (human) & $\begin{array}{l}\text { HepG2 coexpression, } \\
\text { human hepatocytes RNAi } \\
\text { knockdown }\end{array}$ & $\begin{array}{l}\text { S-Warfarin 7-hydroxylase and } \\
\text { diclofenac } 4^{\prime} \text {-hydroxylase }\end{array}$ & Inhibition & Oda et al., 2011 \\
\hline PGRMC1 (human) & CYP3A4 (human) & $\begin{array}{l}\text { HepG2 coexpression, } \\
\text { human hepatocytes RNAi } \\
\text { knockdown }\end{array}$ & $\begin{array}{l}\text { Testosterone } 6 \beta \text {-hydroxylase } \\
\text { and midazolam } 1^{\prime} \text {-hydroxylase }\end{array}$ & Inhibition & Oda et al., 2011 \\
\hline PGRMC1 (human) & CYP2E1 (human) & $\begin{array}{l}\text { HepG2 coexpression, } \\
\text { human hepatocytes RNAi } \\
\text { knockdown }\end{array}$ & $\begin{array}{l}\text { Chlorzoxazone 6-hydroxylase } \\
\text { and 7-ethoxycoumarin } \\
\text { O-deethylase }\end{array}$ & No influence & Oda et al., 2011 \\
\hline PGRMC2 (human) & CYP3A4 (human) & $\begin{array}{l}\text { Human liver genetic } \\
\text { association }\end{array}$ & Atorvastatin 2-hydroxylase & Inhibition & Klein et al., 2012 \\
\hline CYB5D2 (human) & CYP3A4 (human) & $\begin{array}{l}\text { Hela cell expression and } \\
\text { RNAi knockdown }\end{array}$ & $\begin{array}{l}\text { Luciferin 6' pentafluorobenzyl } \\
\text { ether depentafluorobenzylation }\end{array}$ & Activation & $\begin{array}{l}\text { Bruce and Rybak, } \\
2014\end{array}$ \\
\hline
\end{tabular}

is unknown, whether PGRMC1 abundance in the ER is sufficient for the formation of 1:1 complexes at higher concentrations.

Two studies have investigated the question whether PGRMC1 affects drug metabolizing CYPs functionally. Szczesna-Skorupa and Kemper, using cotransfection and coimmunoprecipitation of FLAG-tagged PGRMC1 with variously tagged rabbit CYP2C2 and human CYP2C8 and CYP3A4 in HEK293 cells could show efficient binding of PGRMC1 to all three CYPs, for CYP2C2 mainly mediated by the cytoplasmic domain (Szczesna-Skorupa and Kemper, 2011). The effect of PGRMC1 on enzymatic activity was tested by siRNA-mediated downregulation of endogenous PGRMC1, and by coexpression with functional CYP plasmids in HEK293 and HepG2 hepatoma cells (Table 1). Surprisingly, the results were quite opposite to those of steroidogenic CYPs, as CYP activities were either unchanged or slightly increased in PGRMC1-deficient cells, but decreased in presence of exogenously expressed PGRMC1. Interestingly, the inhibitory effect could be partially and CYP isoform-dependently reversed by increased expression of POR, also shown to directly interact with PGRMC1. The authors concluded that in contrast to steroidogenic CYPs, PGRMC1 is not required by drug metabolizing CYPs for enzymatic activity and that the CYP differential effects may be explained by the intricate PPI affinities in triple CYP-POR-PGRMC1 systems (Szczesna-Skorupa and Kemper, 2011).

Oda et al. (2011) found differential effects of PGRMC1 cotransfection with CYP2C9, CYP2E1, and CYP3A4 in HepG2 cells. While CYP3A4 had increased $K_{\mathrm{m}}$ and decreased $V_{\max }$ with two different substrates (testosterone and midazolam), CYP2C9 $K_{\mathrm{m}}$ was unchanged but $V_{\max }$ also decreased, and CYP2E1 activity (chlorzoxazone, 7-ethoxycoumarin) remained unchanged. The authors also confirmed direct interactions of PGRMC1 with all three CYPs (Oda et al., 2011).

More recently, Kabe et al. (2016) in their structural study investigated the relevance of heme-mediated dimerization on functional interactions with human CYPs. By incubation of FLAG-tagged PGRMC1 with microsomes from insect-cells expressing POR, CYB5, and either CYP1A2 or CYP3A4, they showed by immunoprecipitation that only wild-type PGRMC1 but not the Y113F mutant interacted with the present CYP. The interaction with CYP1A2 was furthermore blocked by incubation with a CO-generating reagent, indicating that 


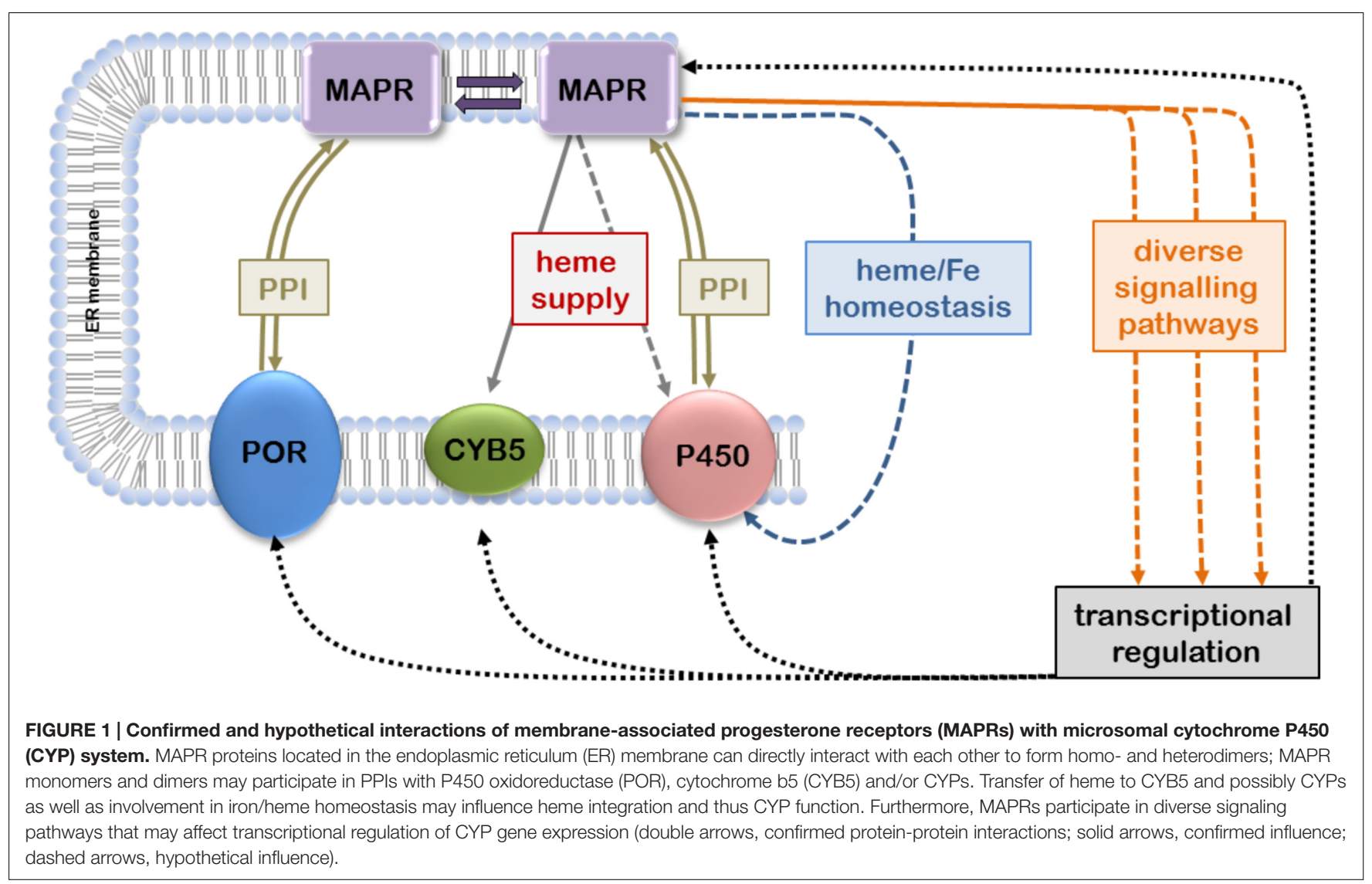

PGRMC1 dimerization is necessary for the interaction. To test whether CYP-mediated enzymatic functions are affected they used HCT116 human colon cancer cells stably expressing control or PGRMC1 shRNA to reduce endogenous PGRMC1 expression and incubated them with doxorubicin. PGRMC1 knock-down suppressed the conversion of doxorubicin to doxorubicinol, and increased cell sensitivity to doxorubicinol. This effect was partially reversed by coexpression of the wild-type PGRMC1 but not of the Y113F mutant. Assuming that CYP2D6 and CYP3A4 are the relevant enzymes for doxorubicinol-formation in HCT116 cells, the authors concluded that interaction of CYPs with the PGRMC1 dimer was a crucial component of CYP activity (Kabe et al., 2016). However, this conclusion is severely flawed because the metabolic step from doxorubicin to doxorubicinol is not a hydroxylation but in fact a 2-electron reduction of a ketogroup to an aliphatic alcohol. This reduction is not catalyzed by CYPs 2D6 and 3A4 as indicated in the paper, but mainly by cytosolic carbonyl reductase 1 (Kassner et al., 2008). Furthermore the use of HCT116 cells with very low CYP3A4 expression seems inappropriate for CYP metabolism studies (Habano et al., 2011). We therefore believe that this and other previously reported functional and cellular effects of PGRMC1 on doxorubicin-metabolism or cytotoxicity (e.g., Friel et al., 2015; Lin et al., 2015) are not due to interactions with CYPs but must have other reasons.

Finally the recent study by Piel et al. (2016) should be mentioned here again as it demonstrated a role of PGRMC1 in heme homeostasis and its ability to directly transfer heme to CYB5 in vitro. The authors suggest that PGRMC1 may be a heme chaperone or sensor, and this could of course have additional direct or indirect implications for CYP function (Figure 1).

\section{PGRMC2}

Despite its high similarity to PGRMC1 much less is known about PGRMC2 (Wendler and Wehling, 2013). The first observation indicating a role in CYP function was made in a pharmacogenetic screen in human livers, where an intronic PGRMC2 polymorphism (rs3733260) was significantly associated with lower levels of mRNA expression, protein and enzyme activity (Klein et al., 2012). Although the directionality of this influence was the same as that observed for PGRMC1 and CYP3A4, it should be noted that the data are correlative in nature and would also be compatible with gene regulatory mechanisms (Figure 1). Stable physical interactions of PGRMC2 were demonstrated in human embryonic kidney cells for CYP1A2 and CYP3A4, suggesting similar interaction potential as for PGRMC1 (Albrecht et al., 2012). It should thus be interesting to investigate the potential of PGRMC2 to modulate CYP function and/or expression in a valid system.

\section{Neudesin and Neuferricin}

To our knowledge, only one study (Bruce and Rybak, 2014) directly addressed the potential interaction of these proteins with CYPs. The authors showed that neuferricin is colocalized 
with POR in HeLa cells. Neuferricin knockdown reduced endogenous CYP51A1 (lanosterol demethylase) protein levels, which lead to increased sensitivity toward mevalonate, an intermediate of the cholesterol synthesis pathway. This suggested a stabilizing role of neuferricin for CYP51A1, as previously described for PGRMC1 and Dap1 (Hughes et al., 2007). Data further indicated that neuferricin knockdown also decreased the fraction of endogenous CYP3A4 activity that was enhanced by overexpressed POR, indicating activation of CYP3A4 by neuferricin, in contrast to the inhibitory effects of PGRMC1 (see above). However, it should be pointed out that the neuferricin data consists of a single point measurement carried out in a cell model that is not usually applied for drug metabolism studies, leaving it unclear whether the conclusion can be generalized. The same argument applies to the studies on HeLa cell exposure to chemotherapeutic agents such as paclitaxel, cisplatin, and doxorubicin, which resulted in increased sensitivities in CYB5D2 deficient cells (Bruce and Rybak, 2014). Since the expression levels of drug metabolizing CYPs are very low in HeLa cells, the construction of a link between CYB5D2 and function of drug metabolizing CYPs based on these data is in our opinion questionable.

\section{CONCLUSION AND FUTURE PERSPECTIVES}

Direct physical interactions of MAPRs, especially of mammalian PGRMC1 or yeast Dap1, with various cytochromes P450 are

\section{REFERENCES}

Ahmed, I. S., Rohe, H. J., Twist, K. E., and Craven, R. J. (2010). Pgrmc1 (Progesterone receptor membrane component 1) associates with epidermal growth factor receptor and regulates erlotinib sensitivity. J. Biol. Chem. 285, 24775-24782. doi: 10.1074/jbc.M110.134585

Ahmed, I. S. A., Chamberlain, C., and Craven, R. J. (2012). S2R(Pgrmc1): the cytochrome-related sigma-2 receptor that regulates lipid and drug metabolism and hormone signaling. Expert Opin. Drug Metab. Toxicol. 8, 361-370. doi: 10.1517/17425255.2012.658367

Albrecht, C., Huck, V., Wehling, M., and Wendler, A. (2012). In vitro inhibition of SKOV-3 cell migration as a distinctive feature of progesterone receptor membrane component type 2 versus type 1. Steroids $77,1543-1550$. doi: 10.1016/j.steroids.2012.09.006

Backes, W. L., and Kelley, R. W. (2003). Organization of multiple cytochrome P450s with NADPH-cytochrome P450 reductase in membranes. Pharmacol. Ther. 98, 221-233. doi: 10.1016/S0163-7258(03) 00031-7

Bruce, A., and Rybak, A. P. (2014). CYB5D2 requires heme-binding to regulate heLa cell growth and confer survival from chemotherapeutic agents. PLOS ONE 9:e86435. doi: 10.1371/journal.pone.0086435

Cahill, M. A. (2007). Progesterone receptor membrane component 1: an integrative review. J. Steroid Biochem. Mol. Biol. 105, 16-36. doi: 10.1016/j.jsbmb.2007. 02.002

Cahill, M. A., Jazayeri, J. A., Catalano, S. M., Toyokuni, S., Kovacevic, Z., and Des Richardson, R. (2016). The emerging role of progesterone receptor membrane component 1 (PGRMC1) in cancer biology. Biochim. Biophys. Acta 1866, 339-349. doi: 10.1016/j.bbcan.2016.07.004

Cai, H. L., Tan, Q. Y., Jiang, P., Dang, R. L., Xue, Y., Tang, M. M., et al. (2015). A potential mechanism underlying atypical antipsychotics-induced lipid disturbances. Transl. Psychiatry 5:e661. doi: 10.1038/tp.2015.161 strongly supported by experimental data. However, data are still limited and in our view use of inappropriate model systems questions some conclusions on functional interactions with CYPs. Open questions that remain to be studied are, for example: which direct MAPR-CYP interactions are possible in binary, ternary, and higher order complexes and how do they affect function; how could MAPRs indirectly influence CYP function, e.g., by regulating heme supply and protein stability; are there MAPR signaling pathways that affect transcriptional regulation of CYPs and possibly other drug metabolizing enzymes, etc. It is of eminent importance that valid experimental systems, which express the CYP system at physiological levels, e.g., primary hepatocytes or genetically modified mice, are used in future studies.

\section{AUTHOR CONTRIBUTIONS}

All authors listed have made substantial, direct and intellectual contribution to the work, and approved it for publication.

\section{FUNDING}

Supported by the National Research Foundation of Korea, Ministry of Education (Basic Science Research Program grant No. 2015R1A6A3A03015840 to CR), the Alexander von Humboldt Foundation (Postdoctoral Research Fellowship to CR), and by the Robert Bosch Foundation, Stuttgart, Germany.

Chen, C., Sargent, C., Quilter, C., Yang, Z., Ren, J., Affara, N., et al. (2010). Cloning, mapping and molecular characterization of porcine progesterone receptor membrane component 2 (PGRMC2) gene. Genet. Mol. Biol. 33, 471-474. doi: 10.1590/S1415-47572010005000057

Craven, R. J., Mallory, J. C., and Hand, R. A. (2007). Regulation of iron homeostasis mediated by the heme-binding protein Dap1 (damage resistance protein 1) via the P450 rotein Erg11/Cyp51. J. Biol. Chem. 282, 36543-36551. doi: 10.1074/ jbc.M706770200

Friel, A. M., Zhang, L., Pru, C. A., Clark, N. C., McCallum, M. L., Blok, L. J., et al. (2015). Progesterone receptor membrane component 1 deficiency attenuates growth while promoting chemosensitivity of human endometrial xenograft tumors. Cancer Lett. 356, 434-442. doi: 10.1016/j.canlet.2014.09.036

Gerdes, D., Wehling, M., Leube, B., and Falkenstein, E. (1998). Cloning and tissue expression of two putative steroid membrane receptors. Biol. Chem. 379, 907-911.

Habano, W., Gamo, T., Terashima, J., Sugai, T., Otsuka, K., Wakabayashi, G., et al. (2011). Involvement of promoter methylation in the regulation of Pregnane $\mathrm{X}$ receptor in colon cancer cells. BMC Cancer 11:81. doi: 10.1186/1471-2407$11-81$

Han, K. H., Lee, S. H., Ha, S. A., Kim, H. K., Lee, C., Kim, D. H., et al. (2012). The functional and structural characterization of a novel oncogene GIG47 involved in the breast tumorigenesis. BMC Cancer 12:274. doi: 10.1186/1471-240712-274

Hand, R. A., Jia, N., Bard, M., and Craven, R. J. (2003). Saccharomyces cerevisiae Daplp, a novel DNA damage response protein related to the mammalian membrane-associated progesterone receptor. Eukaryot. Cell 2, 306-317. doi: 10.1128/EC.2.2.306-317.2003

Hasegawa, S., Kasubuchi, M., Terasawa, K., and Kimura, I. (2016). Perspectives on membrane-associated progesterone receptors as prospective therapeutic targets. Curr. Drug Targets 17, 1189-1197. doi: $10.2174 / 1389450116666150518102651$ 
Henderson, C. J., McLaughlin, L. A., Scheer, N., Stanley, L. A., and Wolf, C. R. (2015). Cytochrome b5 is a major determinant of human cytochrome P450 CYP2D6 and CYP3A4 activity in vivo. Mol. Pharmacol. 87, 733-739. doi: 10.1124/mol.114.097394

Hughes, A. L., Powell, D. W., Bard, M., Eckstein, J., Barbuch, R., Link, A. J., et al. (2007). Dap1/PGRMC1 binds and regulates cytochrome P450 enzymes. Cell Metab. 5, 143-149. doi: 10.1016/j.cmet.2006.12.009

Intlekofer, K. A., and Petersen, S. L. (2011). Distribution of mRNAs encoding classical progestin receptor, progesterone membrane components 1 and 2, serpine mRNA binding protein 1 , and progestin and adipoQ receptor family members 7 and 8 in rat forebrain. Neuroscience 172, 55-65. doi: 10.1016/j. neuroscience.2010.10.051

Izzo, N. J., Xu, J., Zeng, C., Kirk, M. J., Mozzoni, K., Silky, C., et al. (2014). Alzheimer's therapeutics targeting amyloid beta 1-42 oligomers II: Sigma2/PGRMC1 receptors mediate abeta 42 oligomer binding and synaptotoxicity. PLoS ONE 9:e111899. doi: 10.1371/journal.pone.0111899

Kabe, Y., Nakane, T., Koike, I., Yamamoto, T., Sugiura, Y., Harada, E., et al. (2016). Haem-dependent dimerization of PGRMC1/Sigma-2 receptor facilitates cancer proliferation and chemoresistance. Nat. Commun. 7:11030. doi: 10.1038/ ncomms 11030

Kaluka, D., Batabyal, D., Chiang, B.-Y., Poulos, T. L., and Yeh, S. R. (2015). Spectroscopic and mutagenesis studies of human PGRMC1. Biochemistry 54, 1638-1647. doi: 10.1021/bi501177e

Kandel, S. E., and Lampe, J. N. (2014). Role of protein-protein interactions in cytochrome P450-mediated drug metabolism and toxicity. Chem. Res. Toxicol. 27, 1474-1486. doi: 10.1021/tx500203s

Kassner, N., Huse, K., Martin, H. J., Gödtel-Armbrust, U., Metzger, A., Meineke, I., et al. (2008). Carbonyl reductase 1 is a predominant doxorubicin reductase in the human liver. Drug Metab. Dispos. 36, 2113-2120. doi: 10.1124/dmd.108. 022251

Kimura, I., Nakayama, Y., Konishi, M., Kobayashi, T., Mori, M., Ito, M., et al. (2010). Neuferricin, a novel extracellular heme-binding protein, promotes neurogenesis. J. Neurochem. 112, 1156-1167. doi: 10.1111/j.1471-4159.2009. 06522.x

Kimura, I., Nakayama, Y., Konishi, M., Terasawa, K., Ohta, M., Itoh, N., et al. (2012). Functions of MAPR (membrane-associated progesterone receptor) family members as heme/steroid-binding proteins. Curr. Protein Pept. Sci. 13, 687-696. doi: 10.2174/138920312804142110

Kimura, I., Yoshioka, M., Konishi, M., Miyake, A., and Itoh, N. (2005). Neudesin, a novel secreted protein with a unique primary structure and neurotrophic activity. J. Neurosci. Res. 79, 287-294. doi: 10.1002/jnr.20356

Klein, K., Thomas, M., Winter, S., Nussler, A. K., Niemi, M., Schwab, M., et al. (2012). PPARA: a novel genetic determinant of CYP3A4 in vitro and in vivo. Clin. Pharmacol. Ther. 91, 1044-1052. doi: 10.1038/clpt.2011.336

Laird, S. M., Vinson, G. P., and Whitehouse, B. J. (1988). Monoclonal antibodies against rat adrenocortical cell antigens. Acta Endocrinol. 119, 420-426. doi: $10.1530 /$ acta.0.1190420

Lauschke, V. M., and Ingelman-Sundberg, M. (2015). Precision medicine and rare genetic variants. Trends Pharmacol. Sci. 37, 85-86. doi: 10.1016/j.tips.2015. 10.006

Li, X., Rhee, D. K., Malhotra, R., Mayeur, C., Hurst, L. A., Ager, E., et al. (2016). Progesterone receptor membrane component-1 regulates hepcidin biosynthesis. J. Clin. Invest. 126, 389-401. doi: 10.1172/JCI83831

Lin, S.-T., May, E. W. S., Chang, J.-F., Hu, R.-Y., Wang, L. H.-C., and Chan, H.-L. (2015). PGRMC1 contributes to doxorubicin-induced chemoresistance in MES-SA uterine sarcoma. Cell. Mol. Life Sci. 72, 2395-2409. doi: 10.1007/ s00018-014-1831-9

Losel, R., Besong, D., Peluso, J., and Wehling, M. (2008). Progesterone receptor membrane component 1-Many tasks for a versatile protein. Steroids 73, 929-934. doi: 10.1016/j.steroids.2007.12.017

Mallory, J. C., Crudden, G., Johnson, B. L., Mo, C., Pierson, C. A., Bard, M., et al. (2005). Daplp, a heme-binding protein that regulates the cytochrome P450 protein Erg11p/Cyp51p in Saccharomyces cerevisiae. Mol. Cell. Biol. 25, 1669-1679. doi: 10.1128/MCB.25.5.1669-1679.2005

McCallum, M. L., Pru, C. A., Niikura, Y., Yee, S.-P., Lydon, J. P., Peluso, J. J., et al. (2016). Conditional ablation of progesterone receptor membrane component 1 results in subfertility in the female and development of endometrial cysts. Endocrinology 157, 3309-3319. doi: 10.1210/en.2016-1081
Meyer, C., Schmid, R., Scriba, P. C., and Wehling, M. (1996). Purification and partial sequencing of high-affinity progesterone-binding site(s) from porcine liver membranes. Eur. J. Biochem. 239, 726-731. doi: /10.1111/j.1432-1033. 1996.0726u.x

Meyer, U. A. (2004). Pharmacogenetics - five decades of therapeutic lessons from genetic diversity. Nat. Rev. Genet. 5, 669-676. doi: 10.1038/ $\operatorname{nrg} 1428$

Mifsud, W., and Bateman, A. (2002). Membrane-bound progesterone receptors contain a cytochrome b5-like ligand-binding domain. Genome Biol. 3, research0068.1-research0068.5. doi: 10.1186/gb-2002-3-12-research0068

Min, L., Strushkevich, N. V., Harnastai, I. N., Iwamoto, H., Gilep, A. A., Takemori, H., et al. (2005). Molecular identification of adrenal inner zone antigen as a heme-binding protein. FEBS J. 272, 5832-5843. doi: 10.1111/j.17424658.2005.04977.x

Min, L., Takemori, H., Nonaka, Y., Katoh, Y., Doi, J., Horike, N., et al. (2004). Characterization of the adrenal-specific antigen IZA (inner zone antigen) and its role in the steroidogenesis. Mol. Cell. Endocrinol. 215, 143-148. doi: 10.1016/ j.mce.2003.11.025

Mir, S. U. R., Schwarze, S. R., Jin, L., Zhang, J., Friend, W., Miriyala, S., et al. (2013). Progesterone receptor membrane component 1/Sigma-2 receptor associates with MAP1LC3B and promotes autophagy. Autophagy 9, 1566-1578. doi: 10.4161/auto. 25889

Neubauer, H., Clare, S. E., Wozny, W., Schwall, G. P., Poznanoviæ, S., Stegmann, W., et al. (2008). Breast cancer proteomics reveals correlation between estrogen receptor status and differential phosphorylation of PGRMC1. Breast Cancer Res. 10:R85. doi: 10.1186/bcr2155

Neubauer, H., Ma, Q., Zhou, J., Yu, Q., Ruan, X., Seeger, H., et al. (2013). Possible role of PGRMC1 in breast cancer development. Climacteric 16, 509-513. doi: 10.3109/13697137.2013.800038

Oda, S., Nakajima, M., Toyoda, Y., Fukami, T., and Yokoi, T. (2011). Progesterone receptor membrane component 1 modulates human cytochrome $\mathrm{P} 450$ activities in an isoform-dependent manner. Drug Metab. Dispos. 39, 2057-2065. doi: 10.1124/dmd.111.040907

Ohta, H., Kimura, I., Konishi, M., and Itoh, N. (2015). Neudesin as a unique secreted protein with multi-functional roles in neural functions, energy metabolism, and tumorigenesis. Front. Mol. Biosci. 2:24. doi: 10.3389/fmolb. 2015.00024

Pandey, A. V., and Fluck, C. E. (2013). NADPH P450 oxidoreductase: structure, function, and pathology of diseases. Pharmacol.Ther. 138, 229-254. doi: 10.1016/j.pharmthera.2013.01.010

Peluso, J. J., Griffin, D., Liu, X., and Horne, M. (2014). Progesterone receptor membrane component-1 (PGRMC1) and PGRMC-2 interact to suppress entry into the cell cycle in spontaneously immortalized rat granulosa cells. Biol. Reprod. 91:104. doi: 10.1095/biolreprod.114.12 2986

Piel, R. B., Shiferaw, M. T., Vashisht, A. A., Marcero, J. R., Praissman, J. L., Phillips, J. D., et al. (2016). A novel role for progesterone receptor membrane component 1 (PGRMC1): a partner and regulator of ferrochelatase. Biochemistry 55, 5204-5217. doi: 10.1021/acs.biochem.6b00756

Raza, F. S., Takemori, H., Tojo, H., Okamoto, M., and Vinson, G. P. (2001). Identification of the rat adrenal zona fasciculata/reticularis specific protein, inner zone antigen (IZAg), as the putative membrane progesterone receptor. Eur. J. Biochem. 268, 2141-2147. doi: 10.1046/j.1432-1327.2001. 02096.x

Ruan, X., Zhang, Y., Mueck, A. O., Willibald, M., Seeger, H., Fehm, T., et al. (2017). Increased expression of progesterone receptor membrane component 1 is associated with aggressive phenotype and poor prognosis in ER-positive and negative breast cancer. Menopause 24, 203-209. doi: 10.1097/GME. 0000000000000739

Selmin, O., Lucier, G. W., Clark, G. C., Tritscher, A. M., Vanden Heuvel, J. P., Gastel, J. A., et al. (1996). Isolation and characterization of a novel gene induced by 2,3,7,8-tetrachlorodibenzo-p-dioxin in rat liver. Carcinogenesis 17 , 2609-2615. doi: 10.1093/carcin/17.12.2609

Sueldo, C., Liu, X., and Peluso, J. J. (2015). Progestin and adipoQ receptor 7, progesterone membrane receptor component 1 (PGRMC1) and PGRMC2 and their role in regulating progesterone'sability to suppress human granulosa/luteal cells from entering into the cell cycle. Biol. Reprod. 93:63. doi: 10.1095/ biolreprod.115.131508 
Szczesna-Skorupa, E., and Kemper, B. (2011). Progesterone receptor membrane component 1 inhibits the activity of drug-metabolizing cytochromes P450 and binds to cytochrome P450 reductase. Mol. Pharmacol. 79, 340-350. doi: $10.1124 / \mathrm{mol} .110 .068478$

Wehling, M. (1997). Specific, nongenomic actions of steroid hormones. Annu. Rev. Physiol. 59, 365-393. doi: 10.1146/annurev.physiol.59.1.365

Wendler, A., and Wehling, M. (2013). PGRMC2, a yet uncharacterized protein with potential as tumor suppressor, migration inhibitor, and regulator of cytochrome P450 enzyme activity. Steroids 78, 555-558. doi: 10.1016/j.steroids.2012.12.002

Xie, Y., Bruce, A., He, L., Wei, F., Tao, L., and Tang, D. (2011). CYB5D2 enhances HeLa cells survival of etoposide-induced cytotoxicity. Biochem. Cell Biol. 89, 341-350. doi: 10.1139/o11-004

Xu, J., Zeng, C., Chu, W., Pan, F., Rothfuss, J. M., Zhang, F., et al. (2011). Identification of the PGRMC1 protein complex as the putative sigma-2 receptor binding site. Nat. Commun. 2:380. doi: 10.1038/ncomms1386
Zanger, U. M., and Schwab, M. (2013). Cytochrome P450 enzymes in drug metabolism: regulation of gene expression, enzyme activities, and impact of genetic variation. Pharmacol. Ther. 138, 103-141. doi: 10.1016/j.pharmthera. 2012.12.007

Conflict of Interest Statement: The authors declare that the research was conducted in the absence of any commercial or financial relationships that could be construed as a potential conflict of interest.

Copyright (C) 2017 Ryu, Klein and Zanger. This is an open-access article distributed under the terms of the Creative Commons Attribution License (CC BY). The use, distribution or reproduction in other forums is permitted, provided the original author(s) or licensor are credited and that the original publication in this journal is cited, in accordance with accepted academic practice. No use, distribution or reproduction is permitted which does not comply with these terms. 